\title{
Go West Young Man: \\ Self-selection and Endogenous Property Rights
}

\author{
Taylor Jaworski \\ University of Arizona \\ Economics Department \\ E-mail: tjaworski@gmail.com
}

\author{
Bart J. Wilson \\ Chapman University \\ Economic Science Institute \\ E-mail:bartwilson@gmail.com
}

July 2010

Abstract: If, as Hume argues, property is a self-referring custom of a group of people, then property rights depend on how that group forms and orders itself. In this paper we investigate how people construct a convention for property in an experiment in which groups of self-selected individuals can migrate between three geographically separate regions. We find that the absence of property rights clearly decreases wealth in our environment and that interest in establishing property rights is a key determinant of the decision to migrate to a new region. Theft is nearly eliminated among migrants, resulting in strong growth, and non-migrants remain in poverty. Thus, self-selection, through the decision to migrate, to form more cooperative groups is essential for establishing property rights.

Key Words: experimental economics, property rights, migration and exit

JEL Classifications: C92, D23, D51, F10

\footnotetext{
* The experiment data and instructions are available upon request. We gratefully acknowledge financial support from the International Foundation for Research in Experimental Economics. This paper has benefited from comments by Peter DeScioli, Erik Kimbrough, Louis Putterman, Vernon Smith, Andrew Smyth, Nat Wilcox, and three anonymous referees. We also wish to thank Jeff Kirchner for his expert software programming.
} 
The conception of property certainly did not fall ready made from heaven.

-- F.A. Hayek, Law, Legislation and Liberty, Volume 1: Rules and Order

\section{Introduction}

Property rights are essential for economic development. Yet the economic and institutional foundations of ownership and transfer are not well understood. According to David Hume, the development of conventions of justice produced the institution of property, which denominates three fundamental laws of human nature: the stability of possession, transference by consent, and the performance of promises. Furthermore, these laws portend that " $[\mathrm{w}]$ here possession has no stability, there must be perpetual war. Where property is not transferred by consent, there can be no commerce. Where promises are not observed, there can be no leagues or alliances" (1740, p. 363). Hence the wealth of nations is built upon such agreements, but we know surprisingly little about why rights to property exist and the process by which they are formed.

The focus of previous research has been on the central role of property rights in dispute resolution (Coase, 1960; Ellickson, 1991), how changes in incentives alter the form of property rights (Demsetz, 1967; Cheung 1970), the variety of existing property rights institutions (Ostrom, 1990), and, in turn, the long-run path of economic growth (North, 1981). Recent empirical studies emphasize the connection between property rights and growth (Acemoglu and Johnson, 2005; Engerman and Sokoloff, 2003), urban land values (Collins and Margo, 2007; Lanjouw and Levy, 2002), labor supply (Field, 2007), and agricultural investment (Alston, Libecap, and Schneider, 1996; Brasselle, Gaspart, and Platteau, 2002; Hornbeck, 2010), in particular settings.

These studies are important contributions to understanding the function of property rights and evaluating the consequences of their absence for economic development. Taking a different approach, this paper uses a laboratory experiment to document the discovery process that creates and sustains the institution of property in the replicated setting in a laboratory. Subjects in our experiment are placed in a world with repeat interaction, gains from exchange, and a relatively open action space. This environment allows subjects to engage in a trial-and-error discovery process and gives them the opportunity to form groups to overcome the poverty of an initial "no property rights" condition. ${ }^{1}$

\footnotetext{
${ }^{1}$ The phrase "no property rights" is not equivalent to "no notion of property rights" among our subjects. Instead, we transplant our subjects from a world with property rights into an experimental world where they must rediscover the
} 
In addition, theft is possible and group formation is endogenous through the decision to move between three geographically separate regions. In two treatments we vary the potential returns to migration. In one treatment, production possibilities are doubled if at least four of the eight subjects undertake the cost of migrating to a new region. In the second treatment, there is no super-additive productivity when individuals migrate to that same region. Hence, by comparing behavior in these two treatments we can distinguish the emergence of property due to increased productivity and predation from the case where property rights emerge in response to predation alone.

The results suggest that self-selection, through the decision to migrate, is essential for realizing the gains from trade. This is important and remarkable in light of the recent literature reviewed in Section 2. Our other findings are (1) the importance of property rights for wealth creation in our environment, (2) the absence of theft among migrants, which suggests a successful mechanism for identifying latent cooperation, and (3) declining theft among nonmigrants, which suggests the potential for reform within initially uncooperative groups.

\section{Previous Work}

\subsection{Specialization and Exchange}

This paper builds on a recent laboratory study by Crockett, Smith, and Wilson (2009; hereafter CSW), in which the subjects in a two-good exchange economy must discover their comparative advantage and develop some system of exchange to support wealth creation. CSW define a weak institutional environment and then explore the conditions of that environment, such as information about the production technology or group size, that enhance or stifle wealth creation.

In other laboratory studies, Kimbrough, Smith, and Wilson explore different aspects of the effect of property rights on the expansion of specialization and exchange. First, by inducing two "histories", one with experimenter enforced property rights and another with no exogenous property rights enforcement, Kimbrough, Smith, and Wilson (2008; hereafter KSWa), find that economies with a history of property rights are substantially more specialized, wealthier, and more equitable, than economies without this history. However, KSWa treat property rights as

\footnotetext{
"rules of the game" and reapply them within their own subject groups. As Crockett, Smith, and Wilson (2009) put it, "we are relying on them to draw upon their individual experiences, as they see fit, to activate their own implicit rules for the novel tasks that we give them. [Throughout] history, people had to learn ways of interfacing with each other in the context in which they lived and to create a social system from the inside based on natural language adapted to economic change."
} 
historically given or not and then explore differences between these two conditions. This approach powerfully demonstrates that groups with fixed size and a history of property rights can uniformly outperform economies without this history. But this raises the question of how a group might order itself to take advantage of specialization and exchange.

In this vein, Kimbrough, Smith, and Wilson (2010; hereafter KSWb) design a laboratory experiment to explore the formation of property rights among subjects in a similar environment with near costless theft. In half of their baseline sessions, subjects establish stable possession and transference by consent to exploit the gains of specialization and exchange. The efficiency of these sessions rivals the wealthiest economies in which theft is exogenously impossible. In marked contrast, in the other half of the sessions possession is not stable and the economies are woefully inefficient (one is over $20 \%$ less efficient than autarky). KSWb then introduce three exogenous enforcement mechanisms as treatments to ascertain whether the bad apples can be brought into line. For example, in one treatment the subjects can, at a cost, block others from taking their goods. In only one out of six sessions is this effective. The remaining sessions, in contrast, tend to be less efficient than when this blocking mechanism is not present.

All three $\mathrm{KSWb}$ mechanisms were constructed on the view that property rights are a procedure by which individuals adjust to exogenous shocks that affect the costs and benefits of internalization versus externalization. KSWb confess that in the design process they did not appreciate how much the success of their treatments would depend on how each mechanism would operate in conjunction with the particular dispositions and impulses of a fixed group of eight subjects. Unless the dispositions rendered the mechanisms unnecessary to begin with, or exactly matched the problematic temperaments that needed to be overcome in a particular economy, KSWb find that the mechanism treatments tend to worsen outcomes.

So it is possible that property rights can fail to emerge, not because there is no latent desire for them among some members of the group, but rather due to the tenuousness of a convention that is based solely on the reciprocal behavior of all members of the group and that is not enforced by a third party. ${ }^{2}$ Migration in our experimental design allows latent cooperators to flee the plunderers and perpetual war to establish stable possession. As experimenters, we then

\footnotetext{
${ }^{2}$ Collins and Margo (2007) present evidence of this fragility in the modern American context. They find that property values fell more in cities that experienced severe riots in the 1960s. Moreover, the losses were localized around the most riot-effected areas within cities. Thus, setting aside the effect of legal regime, the value and security of property rights appear to derive from expectations about a particular group in a particular environment.
} 
have the luxury of varying the potential returns to migration to distinguish between the effect of super-additive productivity and the operation of social convention on the emergence of property rights.

\subsection{Group Formation and Public Goods}

Many institutions that support exchange depend critically on the size and temperaments of the groups governed by the institution. If this is the case, then it is essential to understand the process by which a group forms and orders itself. Free-riding in the context of the provision of public goods has been the focus of many laboratory studies (e.g., Bochet, Page, and Putterman, 2005; Cinyabuguma, Page, and Putterman, 2005; Isaac and Walker, 1988). Most relevant for our results are the studies that have also focused on the effect of endogenous group formation.

Erhart and Keser (1999) show that in a public goods game with migration, subjects willing to cooperate (i.e., contribute to the public good) form groups through migration and these cooperative groups are able to achieve higher contributions levels than noncooperative ones. More recent studies by Coricelli, Fehr, and Fellner (2004), Page, Putterman, and Unel (2005), Ones and Putterman (2007) Ahn, Isaac, and Salmon (2008), Charness and Yang (2008), and Kosfeld, Okada, and Reidl (2009) show these findings are robust to different institutions governing group formation, though the gains are modest and still subject to decay in repeated interactions.

In our experiment, there are gains from trade, violations of property rights by theft, and, finally, migration to form new groups, all of which provide a check on predatory behavior. Thus, our experimental design allows us to explore how groups form to protect and respect property rights in an environment that is quite different from the commonly studied (voluntary contributions) public goods games.

\section{Experimental Design and Procedures}

\subsection{Computer Interface}

Figure 1 displays the computer interface for our experiment. Each subject is endowed with a field and house (highlighted green) and controls a scroll wheel (in the top-center portion of the screen) used to allocate his endowment of time for production of two goods, red and blue. 
Production is displayed in the field, and when the field is selected (highlighted in yellow), its contents, blue and red chit icons, appear in the top-left portion of the screen.

A subject moves units by left-clicking to select them (which turns them yellow) and then right-clicking and dragging them to the desired destination with the right mouse button depressed. Notice, this allows for "theft" since subjects can move units from another subject's house or field into their own house or field. Only units in a subject's own house at the end of each period generate earnings; units not consumed do no carry over to subsequent periods and are wasted.

The information in the top-right portion of the screen summarizes how earnings are calculated, the total profit excluding the current period, the time remaining in the current period, and the current period and phase. In addition, the chat room in the center of the screen allows subjects to send messages to each other, and there is a space below each house to display oneline message that is visible to all subjects. Thus, the consumption of red and blue units is a function of production, chat room messages, and units moved. Finally, the movement of all goods between people is recorded in the chat room, including the quantity and the subjects involved.

\subsection{Environment}

Each experimental session consists of 8 subjects of two types: odd and even. Each type is endowed with technologies for producing red and blue. In each period, subjects are endowed with $T=10$ seconds and choose $t$ seconds to allocate to the production of red and $(10-t)$ seconds to allocate to the production of blue. Odd types produce according to the following functions:

$$
\begin{aligned}
& R_{\text {odd }}=\frac{13}{10 \sqrt{10}} t^{\frac{5}{2}} \approx 0.41 t^{\frac{5}{2}} \\
& B_{\text {odd }}=\frac{10}{10-((300 \sqrt{10}) 13)^{15}}(10-t) \approx 2.25(10-t)
\end{aligned}
$$

And even types produce according to these functions:

$$
R_{\text {even }}=\frac{13}{10-\sqrt{260 / 11}} t \approx 2.53 t
$$




$$
B_{\text {even }}=\frac{11}{10}(10-t)^{2}
$$

If an agent allocates the entire endowment $T$ to red (blue), then odd types produce 130 (23) units and even types produce 25 (110) units. Thus, odd types have an absolute advantage in producing red and even types in blue.

Finally, each type derives utility from consuming $r$ red and $b$ blue units in strict complements, subject to integer constraints, according to the following preferences by agent type: $U_{\text {odd }}=\min \{r, 3 b\}$ and $U_{\text {even }}=\min \{2 r, b\}$. Thus, odd subjects earn 3 cents for each combination of 3 red and 1 blue consumed and even subjects earn 2 cents for each combination of 1 red and 2 blue consumed.

\subsection{Institution}

Each session lasts 48 periods, each with two phases: (A) production and (B) exchange and consumption. Before the start of the 10-second production phase, each subject chooses the number of red and blue units to produce by setting $t$, and by the end of the phase all of the units are produced. In the 120-second exchange and consumption phase, agents can send messages through the chat room and move goods to and from each other. The number of red and blue units in an agent's house at the end of exchange and consumption phase determines a subject's earnings for that period.

We refer to each block of 7 periods as a "week" (e.g. week 1 is the first seven periods, week 2 is the second seven periods, etc.) and every $7^{\text {th }}$ period as a "break period" in which there is no production. ${ }^{3}$ We follow CSW's Build8 treatment and increase group size gradually over the first five weeks; increases always result in a balanced number of odd and even subjects in each group. In weeks 1-3, each session consists of four 2-subject groups. In week 4, each session consists of two 4-subject groups. After the final increase in week 5, each session consists of one 8-subject group.

This gradual increase in group size is entirely experimenter controlled. However, starting in week 5, subjects also have access to travel that allows them to migrate between three geographically separated regions: East, Middle, and West. The region layout is such that subjects

\footnotetext{
${ }^{3} \mathrm{CSW}$ report in a footnote that they conducted pilot sessions with unpaid participants and without any rest periods and observed that the participants "could use an intermittent break to relax and reflect upon their experience" (p. 1170).
} 
must always move to the Middle to travel between East and West. Migration allows subjects to change group size endogenously, outside of experimenter control.

The characteristics of each region are displayed in the top-left corner of the screen starting in week 5. In the East and West there is no experimenter/software enforcement of personal property rights. Our treatments vary the production capabilities of subjects in the West (see below) and, in the Middle, subjects are limited to autarky production but property rights are enforced exogenously.

When travel is introduced in week 5 (period 28), an instruction box appears describing the newly visible View and Travel buttons. View allows subjects to see the characteristics of other regions without traveling, and Travel allows subjects to transport their house and field to a new region. The cost of moving is that a subject produces zero units in the first period in a new region; production resumes the following period. Thus, to make it to the West, a subject foregoes two full periods of production and consumption (unless one of those periods is a rest period). ${ }^{4}$

\subsection{Competitive Equilibrium}

The autarky and competitive equilibrium of these economies follows directly from the preferences and production functions. In autarky, odd subjects earn 30 cents and even subjects earn 26 cents per period. In the competitive equilibrium consisting of a single odd and even, the subject-pair fully specializes in their absolute advantaged good, exchange at the competitive price (40 red for 30 blue), and earn 90 and 80 cents per period, respectively. However, the trade equilibrium described above does not hold where the number of odd and even subjects is not equal, due to the introduction of travel, in which case we employ a benchmark of a bilateral trading rule that minimizes waste. Starr (1976) describes a bilateral procedure in which agents exchange repeatedly until the smaller of excess supply or excess demand is exhausted. We use this trading rule since it fits the observed (bilateral) behavior in CSW, and furthermore Kimbrough (2010) demonstrates that simulated agents using this trading rule are indistinguishable from human-subject behavior in experiments with perfectly enforced property rights.

\footnotetext{
${ }^{4}$ In practice, few people in the East strategically move to avoid losing a day of production because the opportunity cost is losing that same production to theft.
} 
First, from their production, agents consume to maximize their autarky utility. The remaining (marginal) red and blue units are then available for trade. Second, agents identify a trading partner, the marginal units available for trade are summed across the two agents, and an optimization routine is applied. Optimization yields an integer solution that allocates units according to agent preferences and minimizes waste. The optimization yields a quantity we refer to as "potential profit."

Note that the optimization yields allocations that are Pareto improvements from autarky given current period production for each subject in the group. Since the allocations implied by the trading rule are Pareto, it is possible for potential profit to be less than actual profit since it is not all but only marginal units that are used to calculate potential profit.

\subsection{Treatment}

In the first four weeks all sessions are identical. All subjects reside in the East as the group size increases from two to four in week 4 (period 21) and from four to eight in week 5 (period 28.) In period 28, we then introduce the ability to travel and the treatment conditions. We refer to the first treatment as Double (session 1-6) and the second as Single (session 7-12).

In Double, subjects produce twice as much in the West as in the East, provided there are at least four subjects in West. This does not necessarily increase earnings, but an odd-even subject-pair completely specialized in their absolute advantages and trading at the competitive price earns 180 and 160 cents, respectively, as opposed to 90 and 80 cents in East. Single provides the same opportunity for travel, but subjects produce according to the same production function as in East.

\subsection{Property Rights and Theft}

Following KSWb, we distinguish theft from other types of movement: exchange, gift, and steal trade (mutual taking with consent which is equivalent to exchange). ${ }^{5}$ We define theft as the

\footnotetext{
${ }^{5}$ Smith (1982) defines property rights through the institution: rules by which "agents may communicate and exchange or transform commodities for the purpose of modifying initial endowments in accordance with private tastes and knowledge" (pp. 924-25). In our experiment, the institution does not enforce property rights in exchange: a subject can remove units from the house or field of another subject. Thus, the presence of theft signals that subjects do not have the exclusive right to exchange commodities in line with their own (private) tastes and knowledge.
} 
unidirectional movement by Person $i$ from Person $j$ to $i$ 's house or field, $i \neq j$, without $j$ 's consent, and calculated the amount of theft (as opposed to steal trading) using the following procedure:

1. Identify each action in which $i$ removed units from $j$ 's house or field.

2. Determine $i$ 's relationship with $j$ through chat room transcripts.

3. Record as steal trade actions by $i$ to which $j$ consented and record remaining actions by $i$ as theft.

Once $i$ and $j$ have established a cooperative relationship, the relationship is terminated if $i$ or $j$ take an action to which the other objects in the chat room. ${ }^{6}$

\subsection{Procedures}

We recruited 96 subjects from the undergraduate population at a large state university and conducted 6 sessions for each treatment. Subjects, with one exception, had no experience in a similar experiment. ${ }^{7}$ Upon arriving in the laboratory subjects were seated at visually isolated computer terminals and read self-paced instructions on their computer screen. Each subject was paid $\$ 7$ for showing up on time, plus what they earned based on decisions in the experiment. Each session lasted approximately 110 minutes after which subjects were paid their full earnings in private. Excluding the show-up payment, mean earnings for the twelve sessions were $\$ 13.65$, with a low of $\$ 2.47$ and a high of $\$ 31.96$.

\section{Hypotheses}

Before period 28 we expect no differences between the Double and Single treatments. Our main predictions concern the differences in our sessions after travel is introduced in period 28. However, we use the data before period 28 to examine the impact of theft on profit and hypothesize that theft will reduce profit. It may seem unnecessary to include this hypothesis, but if data do not bear it out, it becomes difficult to interpret the data after travel becomes possible.

Our experimental design and previous experimental studies suggest further hypotheses regarding cooperation and the emergence of property rights after the introduction of travel. After period 28, the difference in the return to travel between treatments suggests that we should

\footnotetext{
${ }^{6}$ Subjects are not the least bit shy to express their objection and disapproval to the movement of items from their house or field that they did not consent to.

${ }^{7}$ Due to a recruiting error, Person 2 in session 4 participated in a similar experiment. The chat room transcripts reveal that this person did not noticeably improve the performance of another participant by disseminating prior knowledge of design similarities.
} 
observe more subjects moving to West in Double than in Single. A related hypothesis, suggested by Demsetz (1967), is that "property rights develop to internalize externalities when the gains of internalization become larger then the cost of internalization" (p. 350). In other words, institutions to enforce property rights emerge where their benefits, protection from theft, are greater than their costs, monitoring to enforce cooperation. In our experimental design, subjects in Single would only travel when the costs of remaining in the East were high relative to the benefits. Subjects in Single are responding to the high costs of cooperation in the East by traveling to the West, where the potential benefits are no greater but costs, in their estimation, will be lower. Thus, we hypothesize that theft in the West will be lower in Single than in Double.

The final hypothesis suggests a relationship between migrants (to the West) and nonmigrants. Since travel is costly and there is no guarantee that all decisions to migrate will result in higher profit (e.g., because at least three subjects do not follow in Double or no subjects follow in Single), we expect that only subjects willing to cooperate will incur the cost of traveling West. Thus, we hypothesize less theft and more profit for subjects who travel to the West. We will find evidence for or against this hypothesis in the comparison of actual and potential profit, the level of theft in the West versus the East, as well as individual characteristics of migrants and non-migrants.

Our hypotheses can be summarized as follows:

Hypothesis 1 (Theft) Prior to the introduction of travel, more theft reduces profit.

Hypothesis 2 (Demsetz) In the Single treatment, there is less theft in the West than in the Double treatment.

Hypothesis 3 (Selection) There is less theft among migrants than among non-migrants and profits are higher for migrants than for non-migrants.

In the next section, we proceed by observing whether (1) property rights (agreements over the exchange of goods) are positively related to profit, (2) migration is determined, in part, by the potential for reaping gains from exchange, and (3) property rights are more prevalent in the West.

\section{Results}

All sessions are institutionally identical prior to the introduction of travel in week 5 . Thus, we expect behavior across treatments to be similar. Table 1 reports mean specialization, efficiency, 
and theft by treatment for weeks 1-4. Specialization and efficiency are defined in Appendix A. The measure of theft is the quantity of red and blue units removed from a subject's house or field without his consent averaged over each period and group. Comparing the entries in each week there does not appear to be a substantial difference by treatment. Indeed, two-sided Wilcoxon rank sum tests on the means of each variable for pairs and groups of four fail to reject the null hypothesis of equal means across the Double and Single treatments. ${ }^{8}$

The first two columns of Table 2 report profit (earnings) in each of weeks 1-4 for CSW's Build8 treatment and the potential profit implied by applying the trading rule described in Section 3.4. In weeks 1-4, the only difference between the Build8 sessions and our experimental sessions is that we do not enforce property rights. The similarity in the means and standard deviations of these quantities for each week is striking and suggests that the trading rule approximates allocations that are achievable without theft. This brings us to our first finding, a subsidiary result necessary for testing Hypothesis 1.

Finding 1: The potential profit in our twelve sessions without property rights is indistinguishable from actual profit in CSW's Build8 treatment with property rights.

The results of two-sided Wilcoxon rank sum tests comparing potential profit in our sessions to actual profit in CSW for week $1\left(W_{48,40}=625.5, p\right.$-value $=0.0050$, two-sided $)$, week $2\left(W_{48,40}=\right.$ $880.0, p$-value $=0.5040$, two-sided $)$, week $3\left(W_{48,40}=860.5, p\right.$-value $=0.4060$, two-sided $)$, and week $4\left(W_{24,20}=274.0, p\right.$-value $=0.4296$, two-sided $)$, can only reject the null hypothesis of equal means in week 1 . Thus, our measure of potential profit does well in approximating outcomes that are attainable through voluntary exchange.

In the remainder of this section we test our main hypotheses and indicate interesting regularities in the data. To preview, we find strong support for each of Hypotheses 1, 2, and 3. In

\footnotetext{
${ }^{8}$ The results of the Wilcoxon rank sum tests for specialization for week $1\left(W_{24,24}=240.5, p\right.$-value $=0.3324$, twosided $)$, week $2\left(W_{24,24}=227.5, p\right.$-value $=0.2159$, two-sided $)$, week $3\left(W_{24,24}=282.5, p\right.$-value $=0.9179$, two-sided $)$, and week $4\left(W_{12,12}=63, p\right.$-value $=0.6233$, two-sided $)$, cannot reject the null hypothesis for equal means across the Double and Single treatments. Similarly, the results for efficiency for week $1\left(W_{24,24}=334.5, p\right.$-value $=0.3428$, twosided $)$, week $2\left(W_{24,24}=297.5, p\right.$-value $=0.8609$, two-sided $)$, week $3\left(W_{24,24}=239.5, p\right.$-value $=0.3173$, two-sided $)$, and week $4\left(W_{12,12}=239, p\right.$-value $=0.2986$, two-sided $)$, cannot reject the null hypothesis for equal means across Double and Single. Finally, the results for theft for week $1\left(W_{24,24}=275, p\right.$-value $=0.7966$, two-sided $)$, week 2 $\left(W_{24,24}=280, p\right.$-value $=0.8768$, two-sided $)$, week $3\left(W_{24,24}=311, p\right.$-value $=0.6351$, two-sided $)$, and week $4\left(W_{12,12}\right.$ $=81, p$-value $=0.6209$, two-sided), cannot reject the null hypothesis for equal means across Double and Single.
} 
addition, we find that not only is actual profit (earnings) in the West robustly increasing over the course of the experiment, unsurprising given the potential boost to production in Double, but also that the percent of potential profit realized is high.

\subsection{The Impact of Theft on Profit}

Figure 2 plots theft per person in each week: in pairs in weeks 1-3, in groups of four in week 4, and in the East and West in weeks 5-7. In the first four weeks, theft increases gradually from a low of 24 units to a maximum of 109 units per person. In the last three weeks, theft spikes initially in the East, reaching a high of more than 200 units in week 5. Theft subsequently decreases in the East but is never as low as in the West. Figure 2 clearly illustrates the prevalence of theft throughout the experiment and hints that migration may be instrumental in its reduction.

However, we must first discover whether theft is something worth reducing. Is there a significant, negative relationship between profit and theft? To answer this question, we estimate the equation (1) for 48 pairs in weeks 1-3 and 24 groups of four in week 4. ${ }^{9}$ Then later investigate whether endogenous group formation through migration is effective in reducing theft in weeks 5-7. The results are reported in the first two columns of Table 3.

$$
\text { Profit }_{g p}=\alpha_{0}+\alpha_{1} \text { Period }_{g p}+\alpha_{2} \text { Specialization }_{g p}+\alpha_{3} \text { Word }_{g p}+\alpha_{4} \text { Theft }_{g p}+\alpha_{5} \text { Theft }_{g p}^{2}+\eta_{g}+\varepsilon_{g p}
$$

Profit is the natural log of profit per person (plus one) in each group $g$ of two or four subjects in period $p$; Period is an integer counter for each period (omitting the break period); Specialization is the mean rate of specialization; and Words is the mean number of space-delimited strings of characters typed by the subjects. ${ }^{10}$ Theft is the total number of units moved from a person's house or field without his consent and $T h e f t^{2}$ is its square. ${ }^{11}$ Finally, $\boldsymbol{\eta} \sim N\left(0, \sigma_{1}^{2}\right)$ is a random effect for each group $g$.

In pairs and groups of four, an additional unit of theft reduces profit by 0.13 percent. The mean (standard deviation) quantity of theft per period is 66 (167) units in pairs and 77 (131) units in groups of four. Thus, a one standard deviation increase from the mean quantity of theft

\footnotetext{
${ }^{9}$ Importantly, since all of the independent variables in equation (1) are set before the determination of profit, these variables are exogenous to the dependent variable.

${ }^{10}$ We include Words as a measure of sociality; we expect that the more subjects converse with each other, the more cooperation they are able to achieve by increasing specialization and exchange and decreasing plunder.

${ }^{11}$ The prevalence of large quantities of theft led us to control for this effect by including Theft ${ }^{2}$.
} 
reduces profit 22 percent in pairs and 18 percent in groups of four. This effect is diminished by the positive coefficient on $T h e f t^{2}$, however, it is economically small in pairs and statistically insignificant in groups of four. This is evidence for Hypothesis 1, but only measures the effect of theft on deviations from mean profit. How much money is left on the table as a result of theft?

Visual inspection of the data reveals that a considerable portion of potential profit is indeed left on the table. Figure 3 plots the difference between potential and actual profit in the first four weeks. Both potential and actual profit appear to steadily increase. However, subjects appear no better at realizing the full amount of potential profit in week 4 than in week 1 .

To formally assess the contribution of theft to the difference between actual and potential profit we estimate equation (2). The results are reported in the last two columns of Table 3.

$$
\begin{aligned}
\overline{\text { Profit }_{g p}}-\text { Profit }_{g p}=\alpha_{0} & +\alpha_{1} \text { Period }_{g p}+\alpha_{2} \text { Specialization }_{g p}+\alpha_{3} \text { Word }_{g p}+\alpha_{4} \text { Theft }_{g p} \\
& +\alpha_{5} \text { Theft }_{g p}^{2}+\eta_{g}+\varepsilon_{g p}
\end{aligned}
$$

$\overline{\text { Profit }}$ is the natural log of potential profit per person (plus one); the other variables are defined as in equation (1). The results are reported in the second two columns of Table 3.

In pairs, an additional unit of theft increases the ratio of potential to actual profit by 0.17 percent. A one standard deviation increase from the mean quantity of theft increases the gap roughly 30 percent in pairs. This effect is statistically significant at the $1 \%$ level and economically large. The positive coefficient on Theft ${ }^{2}$ only slightly diminishes this effect. Finally, although the coefficient on Theft for groups of four in column 4 is statistically insignificant, the positive sign does cut in our favor. The results of estimating equations (1) and (2) lead to our second finding, which supports Hypothesis 1.

Finding 2: Theft decreases profit and increases the ratio of potential to actual profit. This effect is significant in equation (1) for pairs and groups of four and equation (2) for pairs only.

From Finding 2, we conclude that violations of property rights do indeed have a dramatic negative effect on wealth creation in our economies. By our quantitative definition of the movement of items, the establishment of property rights requires explicit agreements for moving or removing goods, and explicit agreements are only possible through chat room communication. 
Only typed words can be the source of such agreements, thus the presence of chat room communication suggests cooperation and should increase profit.

In Table 3, the coefficient on Words has the predicted sign: an additional word increases profit by 0.69 and 1.1 percent in pairs and groups of four, respectively, and decreases the ratio of potential to actual profit by 0.47 and 0.95 percent. Together with the results on the coefficient for Theft, this demonstrates that even within a relatively weak set of institutional rules, it is possible for our subjects to develop agreements over the transfer of goods with sufficient content to substantially increase profit. Moreover, the ability to communicate through the chat room has the opposite effect of theft, suggesting that communication allows subjects to generate agreements over property rights that work to increase profit.

In the next section we analyze the decision to move West once travel is introduced in week 5. In particular, we are interested in whether characteristics in weeks 1-4, prior to the introduction of travel, predict the decision to move and remain in the West.

\subsection{The Decision To Migrate}

Figure 4 plots the change in the number of subjects in the West by treatment. Unsurprisingly, the data indicate that assignment to the Double treatment is clear predictor of the decision to move west. More interesting, perhaps, are the individual characteristics of subjects that might predict the decision to move and remain in the West. $^{12}$ To analyze this decision we estimate equation (3), in which subject characteristics in week 4 predict the decision to move, InWest, a binary variable that is 1 if the subject was in the West in period 48 (the end of the session) and 0 otherwise:

(3) West $_{\text {is }}=\beta_{0}+\beta_{1}$ Double $_{s}+\beta_{2}$ Specialization $_{i s}+\beta_{3}$ Words $_{i s}+\beta_{4}$ Theft $_{\text {is }}+\mu_{s}+\varepsilon_{\text {is }}$

Double identifies the treatment for session $s$, Specialization4 is the mean rate of specialization, Theft 4 is the mean amount of theft, and Words 4 is the mean number of words, all for each subject $i$ in week 4 before travel is possible. We also include a session random effect $\mu$ $\sim N\left(0, \sigma_{1}^{2}\right)$. Table 4 reports the results, including coefficients and marginal effects.

\footnotetext{
${ }^{12}$ Few subjects spend any substantial time in the Middle.
} 
The last two columns of Table 4 report the marginal effects stratified by the treatment dummy variable. As expected, the strongest predictor of moving to the West is belonging to Double: a discrete change from 0 to 1 increases the probability of moving west by 48.7 percentage points. In addition, the marginal effect of Theft 4 among subjects in Double suggests that an additional unit stolen decreases the probability a subject will move west by 0.13 percentage points. Thus, an additional 146 units of theft (one standard deviation of Theft4 in Double) decreases the probability a subject will move west by 19.0 percentage points. Words 4 also predicts travel among subjects in Double: an additional word increases the probability a subject will move west by 2.6 percentage points. More casually, in the chat room transcripts we frequently observe that "thieves" are rather silent relative to those preyed upon, who are often quite vocal in expressing their disapproval, if not condemnation.

Summarizing, the effect of the Double treatment on the decision to move is substantial. In addition, in Double, theft and typed words are indicative of the characteristics possessed by migrants. However, similar results do not hold for Single. Analysis from the previous section suggested that stealing less and talking more were both characteristics of groups that seemed to have better success establishing property rights. Looking again at Figure 2, we see much less theft in the West than in the East in weeks 5-7. In the final two sections, we analyze the determinants of theft and profit, emphasizing the impact of the migration decision.

\subsection{The Impact of Travel on Theft}

After the introduction of travel, theft in the East spikes in week 5 and then gradually declines. However, even as more and more subjects enter the West, theft remains at relatively low levels. This evidence tentatively suggests that group formation through migration successfully separates property-respecting subjects from the thieves. This subsection establishes the quantitative significance of this effect and the next subsection considers the effect of migration on profit.

To examine the impact of region choice on theft, we estimate equation (4):

(4) TheftPerSubject Tp $_{i p}=\gamma_{0}+\gamma_{1}$ Period $_{i p}+\gamma_{2}$ Specialization $_{i p}+\gamma_{3}$ Words $_{i p}+\gamma_{4}$ Double $_{i}$

$$
+\gamma_{5} \text { Travel }_{i p}+\gamma_{6} \text { Region }_{i p}+\eta_{i}+\varepsilon_{i p}
$$


where TheftPerSubject is the natural log of the quantity of theft of a subject (plus one) divided by the number of subjects in the same region as subject $i$ in period $p$. Thus, independent variables measure the effect on the outcome variable per subject in the same region.

The interpretation of Words, in equation (4) is ambiguous since it is determined contemporaneously with theft. However, our main independent variables of interest are determined before any theft occurs and are thus exogenous to the dependent variable. Double is a dummy variable that is 1 for subjects in the Double treatment and 0 for subjects in Single; Travel is a dummy variable that is 1 if the subject produces nothing due to travel in the previous period and 0 otherwise; Region is a set of dummies to indicate the location of subject $i$ in period $p$. Equation (4) is estimated for individuals from period 30, the first period that subjects could reside in the West, until the end of the session, with random effects for each person $i$. The results are reported in Table 5.

Holding other characteristics constant, subjects in the West steal $64.0\left[=-100 \times\left(e^{1.023}-\right.\right.$ 1)] percent less than subjects in the East. This suggests that one reason subjects may prefer the West at all is the relative absence of theft in that region compared to the East. This confirms the importance of endogenous group formation: by allowing subjects to choose, through migration, a sub-group from among others randomly assigned to their session, subjects can avoid interacting with those who do not share the cooperative characteristics of westbound migrants.

This is analogous to the previous findings that endogenous group formation increases contributions in public good games. However, migration allows our subjects to nearly eliminate theft and establish property rights and then to use these property rights to undergird a system of exchange that rapidly increases wealth. This is astonishing given the complexity of the specialization and exchange task and the utter poverty observed in KSWb.

Equation (4) only captures the effect of region on the level of theft, undifferentiated by treatment. To examine treatment- and region-specific effects we estimate Equation (5).

(5) TheftPerSubject $i p=\gamma_{0}+\gamma_{1}$ Period $_{i p}+\gamma_{2}$ Specialization $_{i p}+\gamma_{3}$ Words $_{i p}+\gamma_{4}$ Double $_{i}$

$$
\begin{aligned}
& +\gamma_{5} \text { Travel }_{i p}+\gamma_{6} \text { Region }_{i p}+\gamma_{7} \text { Period }_{i p} * \text { Double }_{i} \\
& +\gamma_{8} \text { Period }_{i p} * \operatorname{Region~}_{i p}+\gamma_{9} \text { Double }_{i} * \text { Region }_{i p}+\eta_{i}+\varepsilon_{i p}
\end{aligned}
$$


The dependent variable is identical to the dependent variable in equation (4). The interaction variable Period*Double captures changes in theft over time due to the treatments, while Period*Region captures changes due to the location differences. Finally, Double*Region provides a test of our Hypothesis 3: do subjects in the West steal less in Single than in Double?

In Table 5, with the addition of the interaction terms the coefficient on West captures the effect of the West region for subjects in the Single treatment, while the sum of the coefficients on West and Double *West captures the effect for subjects in Double. Subjects in the West steal 94.4 $\left[=-100 \times\left(e^{-2.875}-1\right)\right]$ and $86.0\left[=-100 \times\left(e^{-2.875+0.912}-1\right)\right]$ percent less than subjects in the East in Single and Double, respectively. This shows a strong negative effect of relocating to the West on the quantity of theft for both treatments, but the effect for Single is larger (more negative), as predicted. This provides evidence for our third and fourth findings, which support Hypothesis 2 and Hypothesis 3, respectively.

Finding 3: Theft is lower in the West in Single than in Double.

Finding 4: Theft is significantly lower among subjects in the West than among their counterparts in the East.

We do not want emphasize too strongly the difference between 94.4 and 86.0 percent and overstate the case for Hypothesis 2. More interesting, perhaps, is that the difference between the East and West, whether subjects were assigned to Double or Single, was so dramatic. Subjects moving to the West reduced and nearly eliminated theft, whereas significant levels of theft in the East remain. The final question is whether this reduction in theft is beneficial, i.e., does the establishment of property rights in the West increase profit?

\subsection{The Impact of Travel on Profit}

The previous findings for theft provide partial support for Hypothesis 3: theft is clearly lower among migrants than among non-migrants. Figures 5 and 6 give initial support to the claim that through migration, subjects are able to establish property rights and increase earnings. ${ }^{13}$ The shaded portions in both figures represent the difference between potential and actual profit. The

\footnotetext{
${ }^{13}$ Series stratified by the Double and Single treatments are qualitatively similar.
} 
difference in the two regions couldn't be starker. First, subjects in the West realize profits at levels extremely close to the waste minimizing optimum; there is little waste because there is little theft. The gap, however, between potential and actual profit in the East is initially considerably larger. Interestingly, this gap is shrinking by the last week as theft in the East also begins to decline. Apparently after the plundered have left, the situation becomes dire enough that the plunderers themselves begin to reform.

Second and more noticeable, wealth in the West grows briskly. Having migrated to establish property rights, Westerners take more and more advantage of exchange and specialization, and in the Double treatment, also experience a two-fold increase in production when there are four settlers. Importantly, growth in the West occurs in both Double and Single, in fact, migrants in session 9 are the only migrants to find and maintain the competitive equilibrium, earning the maximum amount possible per period. In the East potential profit falls slightly because the more specialized (and hence productive) subjects have left. The Easterners may be stealing less by the end, but they are not exchanging and specializing more. This hysteresis is reminiscent of what KSWa find in their history of no property rights treatment. With an exogenous history of no property rights, KSWa observe that there is one village in each session which wallows in self-sufficiency even though the software perfectly enforces property rights.

To quantify this effect of location on profit and check that the doubled production possibilities alone are not driving the result we estimate equation (6) with the same independent variables as in equation (5) and over the same portion of the experiment. The results are reported in Table $6 .^{14}$

$$
\begin{aligned}
\text { Profit }_{i p}= & \beta_{0}+\beta_{1} \text { Period }_{i p}+\beta_{2} \text { Specialization }_{i p}+\beta_{3} \text { Words }_{i p}+\beta_{4} \text { Double }_{i}+\beta_{5} \text { Travel }_{i p}+\beta_{6} \text { Region }_{i p} \\
& +\beta_{7} \text { Period }_{i p} * \text { Double }_{i}+\beta_{8} \text { Period }_{i p} * \text { Region }_{i p}+\beta_{9} \text { Double }_{i} * \text { Region }_{i p}+\eta_{i}+\varepsilon_{i p}
\end{aligned}
$$

Profit is natural log of profit (plus one) earned by subject $i$ in period $p$.

From Table 6, holding other characteristics constant, subjects in the West in either treatment earn roughly $240\left[=100 \times\left(e^{1.243}-1\right)\right]$ percent more than subjects in the East. Note that the coefficient on Double*West is insignificant, which suggests that the gains experienced by

\footnotetext{
${ }^{14} \mathrm{We}$ also estimate a similar equation that excludes the interaction variables. The results are reported in Table 6.
} 
westerners are not driven entirely by the super-additive production enjoyed by subjects in Double. The insignificant coefficient on Period*West indicates that this level difference between the East and the West is not eroding over time. Hence, we find quantitative support for the profit portion of Hypothesis 3:

Finding 5: Profit is significantly higher among subjects in the West than among their counterparts in the East.

\section{Conclusion}

In 1766 the English jurist and professor Sir William Blackstone famously wrote in his Commentaries on the Law of England:

There is nothing which so generally strikes the imagination, and engages the affections of mankind as the right of property; or that sole and despotic dominion which one man claims and exercises to the external things of the world, in the total exclusion of the right of any other individual in the universe. And yet there are very few, that will give themselves the trouble to consider the origin and foundation of this right. Pleased as we may be with the possession, we seem to be afraid to look back to the means by which it was acquired, as if fearful of some defects in our title; or at best we rest satisfied with the decision of the laws in our favor, without examining the reason or authority upon which those laws have been built. (Book II, Ch. 1, p. 2)

This paper is an attempt to uncover the foundations upon which the law of property has been built. We report a laboratory experiment designed to explore how property rights emerge as a convention when people can self-select to form their own communities through geographic migration. When given the opportunity, we find that socially-minded individuals leave areas in which the stability of possession, Hume's first fundamental law of human nature, is neither recognized nor respected. Upon resettlement, there is little theft and these migrants become much wealthier than their counterparts as they quickly adhere to Hume's second fundamental law of nature, the transference of property by consent. Surprisingly, we also observe that the plunderers, when left with each other, also begin to establish more stable possession amongst themselves. They, however, engage in little specialization and exchange, and hence remain rather poor. Finally, we find evidence that migrants are sensitive to the difference in benefits from traveling to the West-subjects in Double travel earlier and in greater numbers than subjects in Single - but also to the difference in costs — subjects in Single steal less than subjects in Double.

In conclusion, we observe the first replicable means by which subjects in the laboratory build a system of the property rights: Latent cooperators form communities of like-minded 
individuals by putting physical and social distance between them and the uncooperative plunderers. ${ }^{15}$ Given the paucity with which property emerges in the laboratory when people cannot self-select and migrate, ${ }^{16}$ this is no small feat. This experiment powerfully supports what Samuel Pufendorf discussed in 1672, namely we "too discover the Falsity of that vulgar Saying, Mine and Thine are the cause of all Wars and Quarrels in the World. For on the contrary the Distinction of Mine and Thine was rather introduc'd to prevent all Contention" (Book IV, Ch. 4, Section 7). And it is this necessary distinction that undergirds a fundamental insight of economics, viz., exchange and specialization create the wealth of nations.

\section{References}

Acemoglu, Daron, and Simon Johnson. 2005. "Unbundling Institutions.” Journal of Political Economy, 113(5): 949-995.

Ahn, T.K., R. Mark Isaac, and Timothy C. Salmon. 2008. "Endogenous Group Formation." Journal of Public Economic Theory, 10(2): 171-94.

Alston, Lee J., Gary D. Libecap, and Robert Schneider. 1996 "The Determinants and Impact of Property Rights: Land Titles on the Brazilian Frontier." Journal of Law, Economics, and Organization, 12(1): 25-61.

Blackstone, Sir William. 2003. Commentaries on the Laws of England. The Lawbook Exchange, Ltd.: Clark, NJ.

Bochet, Olivier, Talbot Page, and Louis Putterman. 2006. "Communication and Punishment in Voluntary Contribution Experiments." Journal of Economic Behavior and Organization, 60(1): 11-26.

Brasselle, Anne-Sophie, Frederic Gaspart, and Jean-Philippe Platteau. 2002. "Land Tenure Security and Investment Incentives: Puzzling Evidence from Burkina Faso." Journal of Economic Development, 68(2): 373-418.

Charness, Gary, and Chun-Lei Yang. 2008. "Endogenous Group Formation and Public Goods Provision: Exclusion, Exit, Mergers, and Redemption." Working Paper.

Cheung, Steven. 1970. "The Structure of a Contract and the Theory of a Non-exclusive Resource." Journal of Law and Economics, 13(1): 49-70.

Cinyabuguma, Matthias, Talbot Page, and Louis Putterman. 2005. "Cooperation Under the

\footnotetext{
${ }^{15}$ Cf. 1.

${ }^{16} \mathrm{KSWb}$ conduct 24 sessions with 4 different treatments and roughly observe property emerge in one out of every six sessions.
} 
Threat of Expulsion in a Public Goods Experiment." Journal of Public Economics, 89(8): 1421-35.

Coase, Ronald H. 1960. "The Problem of Social Cost." Journal of Law and Economics, 3(1): 144.

Collins, William J., and Robert A. Margo. 2007. "The Economic Aftermath of the 1960s Riots in American Cities: Evidence from Property Values." Journal of Economic History, 67(4): 849883.

Coricelli, Giorgio, Dietmar Fehr, and Gerlinde Fellner. 2004. "Partner Selection in Public Goods Experiments." Journal of Conflict Resolution, 48(3): 356-378.

Crockett, Sean, Vernon L. Smith, and Bart J. Wilson. 2009. "Exchange and Specialisation as a Discovery Process.” Economic Journal, 119(539): 1162-1188.

Demsetz, Harold. 1967. "Toward a Theory of Property Rights.” American Economic Review, 57(2): 347-359.

Ellickson, Robert C. 1991. Order Without Law: How Neighbors Settle Disputes. Harvard University Press: Cambridge, MA.

Engerman, Stanley, and Kenneth Sokoloff. 2003. "Institutional and Non-institutional Explanations of Economic Differences." In Handbook of New Institutional Economics, Claude Menard and Mary M. Shirley, eds. (Dordrecht, the Netherlands: Springer).

Hornbeck, Richard. 2010. "Barbed Wire: Property Rights and Agricultural Development." Quarterly Journal of Economics, 125(2): 767-810.

Hume, David. 1740 [2000]. A Treatise of Human Nature. Oxford University Press: New York, NY.

Isaac, R. Mark, and James M. Walker. 1988. "Group Size Effects in Provision of Public Goods: The Voluntary Contributions Mechanism." Quarterly Journal of Economics, 103(1): 179199.

Kimbrough, Erik O. 2010. "Learning Specialization and Exchange in Human-Subject Experiments and Agent-Based Models." Working Paper, Chapman University.

Kimbrough, Erik O., Vernon L. Smith, and Bart J. Wilson. 2008. "Historical Property Rights, Sociality, and the Emergence of Personal Exchange in Long-Distance Trade." American Economic Review, 98(3): 1009-1039.

Kimbrough, Erik O., Vernon L. Smith, and Bart J. Wilson. 2010. "Exchange, Theft, and the Social Formation of Property." Journal of Economic Behavior and Organization, 74(3): 206229. 
Kosfeld, Michael, Akira Okada, and Arno Riedl. 2009. "Institution Formation in Public Goods Games." American Economic Review, 99(4): 1335-1355.

Lanjouw, Jean O., and Philip I. Levy. 2002. "Untitled: A Study of Formal and Informal Property Rights in Urban Ecuador.” Economic Journal, 112(482): 986-1019.

North, Douglass. 1982. Structure and Change in Economic History. WW Norton: New York, NY.

Ones, Umut, and Louis Putterman. 2007. "The Ecology of Collective Action: A Public Goods and Sanctions Experiment with Controlled Group Formation." Journal of Economic Behavior and Organization, 62(4): 495-521.

Ostrom, Elinor. 1990. Governing the Commons: The Evolution of Institutions of Collective Action. Cambridge University Press: New York, NY.

Page, Talbot, Louis Putterman, and Bulent Unel. 2005. "Voluntary Association in Public Goods Experiments: Reciprocity, Mimicry, and Efficiency." Economic Journal 115(506): 10321053.

Pinheiro, Jose, Douglas Bates, Saikat DebRoy, Deepayan Sarkar and the R Development Core Team. 2008. nlme: Linear and Nonlinear Mixed Effects Models. R package version 3.1-89.

Pufendorf, Samuel von. 1672 [2005]. Of the Law of Nature and Nations: Eight Books. The Lawbook Exchange, Ltd.: Clark, NJ.

R Development Core Team. 2008. R: A Language and Environment for Statistical Computing. R Foundation for Statistical Computing: Vienna, Austria. ISBN 3-90051-0-0, URL http://www.R-project.org.

Smith, Vernon L. 1982. "Microeconomic Systems as an Experimental Science." American Economic Review, 72(5): 923-955.

Starr, Ross M. 1976. “Decentralized Nonmonetary Trade.” Econometrica, 44(5): 1087-1089. 


\section{Appendix}

\section{A . Specialization and Efficiency}

We define specialization in our economies as $\frac{\sum_{i \in S} q_{i p}}{\sum_{i \in S} \bar{q}_{i p}} \times 100 \%$, where $q_{i p}$ denotes the total units of red and blue produced by subject $i$ in period $p$ of session $S$ and $\bar{q}_{i p}$ denotes the maximum production of red and blue units by $i$ in $p$.

We define efficiency in our economies as $\frac{\sum_{i \in S} \pi_{i p}-\sum_{i \in S} \pi_{i}^{a}}{\sum_{i \in S} \pi_{i p}^{c}-\sum_{i \in S} \pi_{i}^{a}} \times 100 \%$, where $\pi_{i p}$ is realized earnings of subject $i$ in period $p$ of session $S$, and $\pi_{i}^{a}$ and $\pi_{i}^{c}$ are autarky and competitive earnings, respectively. Autarky earnings are subtracted from realized and competitive earnings to normalize autarky efficiency to zero.

\section{B. Experiment Instructions}

\section{Page 1}

This is an experiment in the economics of decision making. The instructions are simple, and if you follow them carefully and make good decisions you may earn a considerable amount of money which will be paid to you in CASH at the end of the experiment.

In this experiment you are Person 3. You and the other 7 people in this experiment each have the ability to produce two fictitious items: red and blue. For the first $\mathbf{1 0}$ seconds of each period, you will produce items in your green field. Using the scroll bar in the upper middle portion of your screen, you can change the proportion of each second allocated to producing red and blue. Each person's production is displayed on their field. When a field or house is selected it contents is represented by the domino-shapes in the top left portion of your screen. To select a field or house left click on it, the house or field that is currently selected will be highlighted in yellow.

\section{Page 2}

After the production phase ends, the period continues for another $\mathbf{9 0}$ seconds. When the clock expires, you earn cash based upon the number of red and blue items that have been moved to your house. To select items to be moved, left click on the dominos or click on the red or blue select all buttons at the top of the screen. The yellow highlighted items can be moved by dragging with the right mouse button. The maximum number of red or blue items a house or field can hold is 170. (You cannot move items until the experiment has started or during the production phase.)

The specific information on how the red and blue items in your house generate earnings is given in the upper right corner of your screen. You personally earn (in cents) the minimum of the following two numbers: 
3 time number of red items, number of blue items.

Or, think of it this way. You earn by consuming what's in your house in the proportion of 3 red to 1 blue items. For every 1 unit of blue you need 3 red to earn 3 cents. Your potential profit updates as items, unit by unit, are moved into your house.

\section{Page 3}

Everyone in this experiment can send text messages. Everyone can read all posted messages. In the center of the screen, you can type a message in the text box next to the send button. To send a text message press the Send button. There are two chat rooms. Messages sent to Chat Room A will only appear in chat room A. Message sent to Chat Room B will only appear in chat room B

Under your house you can also post a one-line message that will be visible at all times to the other players.

You are free to discuss all aspects of the experiment, with the following exceptions: you may not reveal your name, discuss side payments, make threats, or engage in inappropriate language (including such shorthand as 'WTF'). If you do, you will be excused and you will forfeit your earnings.

\section{Page 4}

During the experiment, every 7 periods will be a "break period" in which nobody produces anything but that the chat rooms are still open. You can open a table of your production possibilities by clicking on the Show $\% \mathrm{~s}$ button. This table will fill in every time you change the proportion of time allocated using the scroll bar.

This is the end of the instructions. If you wish to explore how you produce red and blue items, click the Practice button. You may change the proportion of time allocated to producing red and blue items using the scroll bar, and you may Practice as many times as you wish. (You will not be able to move items until the experiment has begun.)

If you wish to review the instructions, you may go back at this time. If you feel you are prepared to proceed with the actual experiment, click on the Start button. The experiment will begin once everyone has clicked on the Start button. If you have a question that you feel was not adequately answered by the instructions, please raise your hand and ask the monitor before proceeding. 


\begin{tabular}{l|ll|ll|lc}
\hline \hline & \multicolumn{2}{c}{ Specialization } & \multicolumn{2}{c}{ Efficiency } & \multicolumn{2}{c}{ Theft } \\
\hline & Double & Single & Double & Single & Double & Single \\
\hline \hline Week 1 & $36_{ \pm 4.8}$ & $39_{ \pm 4.9}$ & $-20_{ \pm 4.8}$ & $-19_{ \pm 7.2}$ & $345_{ \pm 374.9}$ & $373_{ \pm 327.9}$ \\
Week 2 & $41_{ \pm 11.2}$ & $44_{ \pm 7.5}$ & $-11_{ \pm 12.0}$ & $-10_{ \pm 8.9}$ & $593_{ \pm 601.2}$ & $634_{ \pm 266.6}$ \\
Week 3 & $49_{ \pm 11.6}$ & $53_{ \pm 15.6}$ & $0_{ \pm 14.8}$ & $15_{ \pm 23.2}$ & $723_{ \pm 1011.1}$ & $500_{ \pm 468.8}$ \\
Week 4 & $55_{ \pm 14.7}$ & $62_{ \pm 24.5}$ & $9_{ \pm 16.8}$ & $25_{ \pm 37.4}$ & $719_{ \pm 617.2}$ & $520_{ \pm 537.0}$ \\
\hline
\end{tabular}

Table 1: Specialization, efficiency, and theft by treatment. Standard deviations are reported in smaller text following the \pm sign.

\begin{tabular}{l|ll|lc}
\hline \multicolumn{2}{c}{} & \multicolumn{2}{c}{ Profit } & \multicolumn{2}{c}{ Rank Sum Test } \\
\hline \hline Week 1 & Build8 & Potential Profit & $W$-statistic & $p$-value \\
Week 2 & $22_{ \pm 6.5}$ & $26_{ \pm 8.6}$ & 625.5 & 0.0050 \\
Week 3 & $31_{ \pm 15.0}$ & $30_{ \pm 12.6}$ & 880.0 & 0.5040 \\
Week 4 & $37_{ \pm 19.8}$ & $40_{ \pm 24.2}$ & 860.5 & 0.4060 \\
\hline
\end{tabular}

Table 2: Comparison with Crocket, Smith, and Wilson (2009). Standard deviations are reported in smaller text following the \pm sign. In weeks $1-3$, the Wilcoxon rank sum tests are based on 48 independent pairs in from our data and 40 independent pairs from CSW. In week 4, the test is based on 24 and 20 independent groups of four, respectively. 


\begin{tabular}{l|l|l|l|l}
\hline Dependent Variable & \multicolumn{2}{c}{ Profit } & \multicolumn{2}{c}{ Profit - Profit } \\
\hline Group Size & \multicolumn{1}{c}{$(\mathbf{1})$ Two } & \multicolumn{1}{c}{$\mathbf{( 2 )}$ Four } & $(\mathbf{3})$ Two & (4) Four \\
\hline \hline Constant & 1.7305 & 1.6634 & 0.7043 & 1.6765 \\
& $(0.000)$ & $(0.000)$ & $(0.000)$ & $(0.000)$ \\
Period & 0.0233 & 0.0345 & -0.0222 & -0.0103 \\
& $(0.000)$ & $(0.044)$ & $(0.000)$ & $(0.566)$ \\
Specialization & 0.0209 & 0.0179 & -0.0014 & -0.0103 \\
& $(0.000)$ & $(0.000)$ & $(0.425)$ & $(0.000)$ \\
Words & 0.0069 & 0.0107 & -0.0046 & -0.0094 \\
Theft & $(0.064)$ & $(0.034)$ & $(0.186)$ & $(0.113)$ \\
& -0.0013 & -0.0013 & 0.0017 & .0010 \\
Theft ${ }^{2} \div 10000$ & $(0.003)$ & $(0.053)$ & $(0.000)$ & $(0.279)$ \\
& 0.0074 & 0.0152 & -0.0067 & -0.0113 \\
\hline Observations & $(0.045)$ & $(0.122)$ & $(0.056)$ & $(0.373)$ \\
\hline
\end{tabular}

Table 3: Linear mixed-effects regressions for Profit and $\overline{\text { Profit }}$ - Profit. The results of estimating equation (1) in the first two columns and equation (2) in the second two columns. $p$-values reported in parentheses. 


\begin{tabular}{l|c|l|l}
\hline \hline Dependent Variable & \multicolumn{3}{c}{ InWest } \\
\hline \multicolumn{1}{c|}{ Coef. } & Mfx: Single & Mfx: Double \\
\hline \hline Constant & -2.7064 & & \\
& $(0.015)$ & & \\
Double & 2.4639 & & 0.4867 \\
& $(0.030)$ & & $(0.056)$ \\
Specialization4 & 0.0088 & 0.00002 & 0.0005 \\
& $(0.880)$ & $(0.890)$ & $(0.880)$ \\
Words4 & 0.0659 & 0.001214 & 0.0262 \\
& $(0.096)$ & $(0.642)$ & $(0.096)$ \\
Theft4 & -0.0034 & -0.000063 & -0.0014 \\
& $(0.075)$ & $(0.668)$ & $(0.075)$ \\
\hline Observations & 96 & 6 & 23 \\
\hline
\end{tabular}

Table 4: Probit analysis of decision to move West. The results of estimating equation (3). 6 subjects in Single and 23 subjects in Double moved to the West. p-values reported in parentheses. 


\begin{tabular}{|c|c|c|c|c|}
\hline \multirow[t]{2}{*}{ Dependent Variable } & \multicolumn{2}{|c|}{ TheftPerSubject } & \multicolumn{2}{|c|}{ Profit } \\
\hline & (1) & (2) & (3) & $(4)$ \\
\hline \multirow[t]{2}{*}{ Constant } & 1.9397 & 2.5348 & 2.3175 & 2.4195 \\
\hline & $(0.004)$ & $(0.001)$ & $(0.000)$ & $(0.00)$ \\
\hline \multirow[t]{2}{*}{ Period } & -0.0306 & -0.0712 & 0.0382 & 0.0576 \\
\hline & $(0.000)$ & $(0.000)$ & $(0.000)$ & $(0.000)$ \\
\hline \multirow[t]{2}{*}{ Specialization } & 0.0005 & -0.0016 & 0.0062 & 0.0064 \\
\hline & $(0.595)$ & $(0.155)$ & $(0.000)$ & $(0.000)$ \\
\hline \multirow[t]{2}{*}{ Words } & -0.0177 & -0.0168 & -0.0036 & -0.0038 \\
\hline & $(0.000)$ & $(0.000)$ & $(0.321)$ & $(0.299)$ \\
\hline \multirow[t]{2}{*}{ Double } & -0.6789 & -1.2194 & -0.2691 & -0.5237 \\
\hline & $(0.460)$ & $(0.225)$ & $(0.704)$ & $(0.485)$ \\
\hline \multirow[t]{2}{*}{ Travel } & -0.2561 & -0.2562 & -2.1427 & -2.1330 \\
\hline & $(0.073)$ & $(0.070)$ & $(0.000)$ & $(0.000)$ \\
\hline \multirow[t]{2}{*}{ Middle } & -1.4019 & -2.1418 & 0.8526 & 1.3863 \\
\hline & $(0.000)$ & $(0.000)$ & $(0.000)$ & $(0.000)$ \\
\hline \multirow[t]{2}{*}{ West } & -1.0225 & -2.8747 & 1.2311 & 1.2430 \\
\hline & $(0.000)$ & $(0.000)$ & $(0.000)$ & $(0.007)$ \\
\hline \multirow[t]{2}{*}{ Period $*$ Double } & & 0.0464 & & -0.0325 \\
\hline & & $(0.000)$ & & $(0.031)$ \\
\hline \multirow[t]{2}{*}{ Period $*$ Middle } & & 0.0686 & & -0.0038 \\
\hline & & $(0.922)$ & & $(0.089)$ \\
\hline \multirow[t]{2}{*}{ Period $*$ West } & & 0.0869 & & 0.0265 \\
\hline & & $(0.001)$ & & $(0.331)$ \\
\hline \multirow[t]{2}{*}{ Double * Middle } & & 0.0215 & & -0.6350 \\
\hline & & $(0.003)$ & & $(0.020)$ \\
\hline \multirow[t]{2}{*}{ Double $*$ West } & & 0.9120 & & -0.3580 \\
\hline & & $(0.000)$ & & $(0.293)$ \\
\hline Observations & 1632 & 1632 & 1632 & 1632 \\
\hline
\end{tabular}

Table 5: Linear mixed-effects regressions for Theft and Profit. p-values reported in parentheses. 


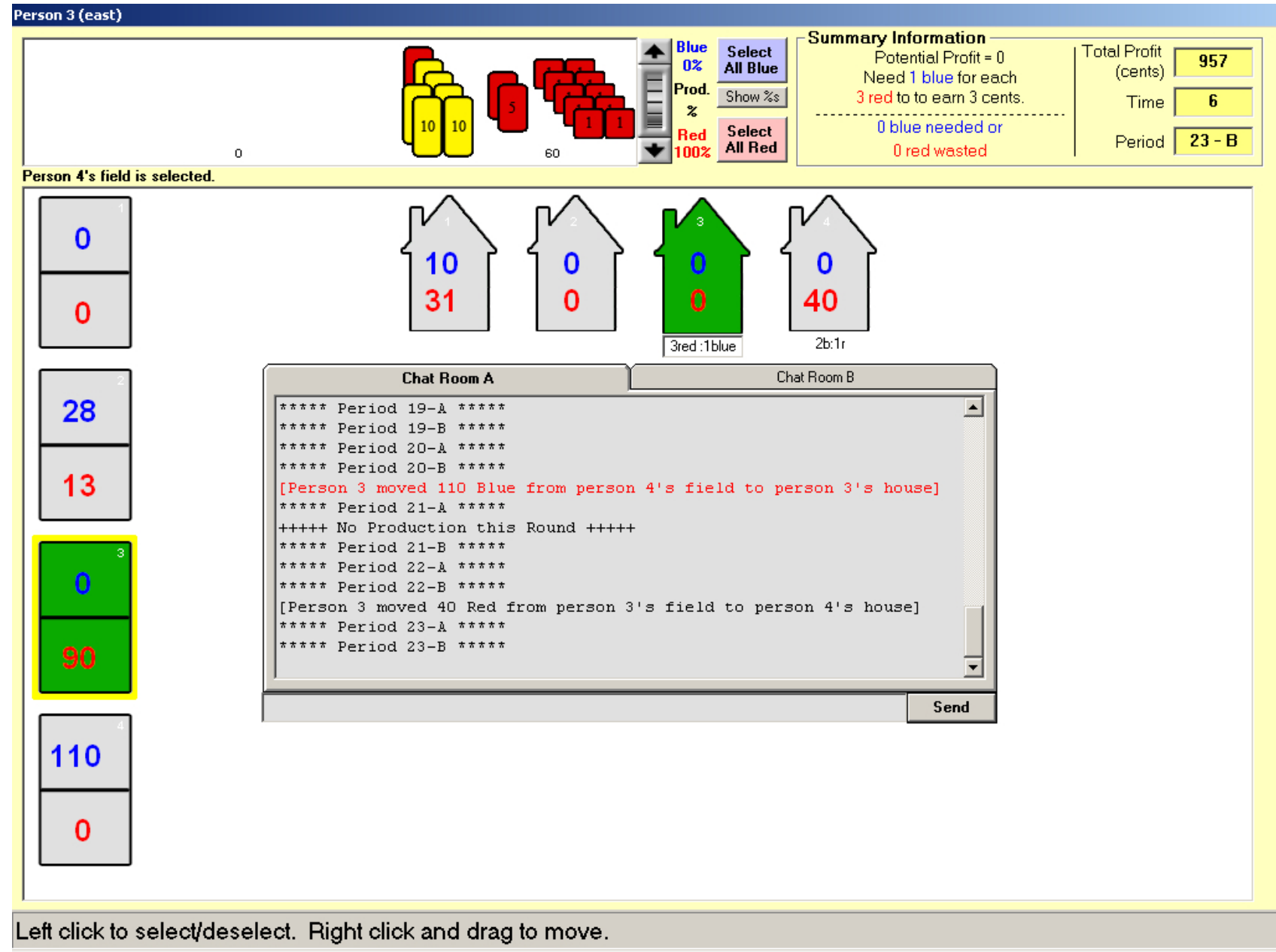

Figure 1. Screenshot of Experimental Interface 


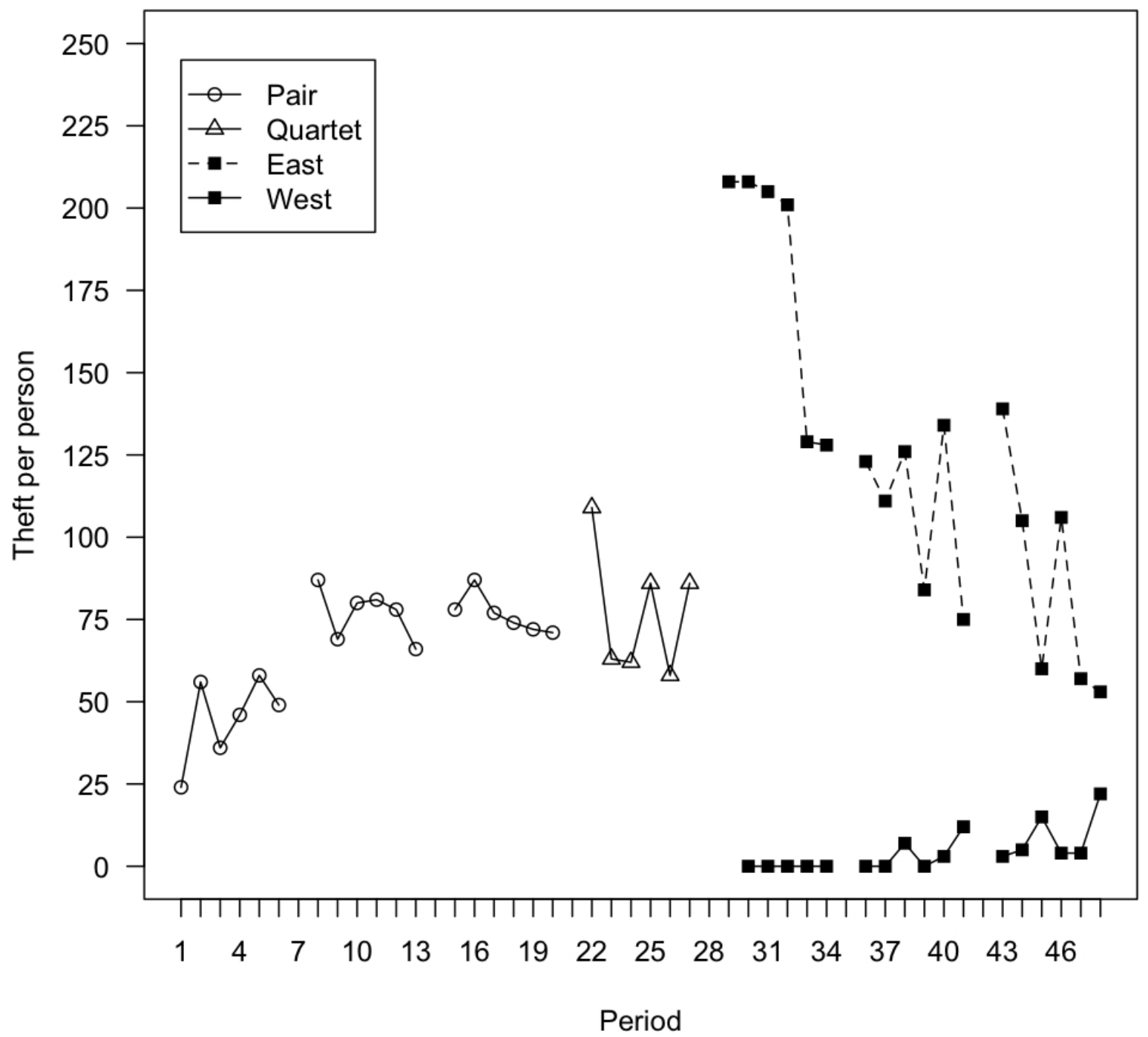

Figure 2. Theft in Week 7

In the first four weeks, theft is calculated by summing total quantity of theft in each period and dividing by 96, the total number of people. In the final three weeks, theft is calculated by summing the total quantity in the East and the West in each period and dividing by the population of the region in each period. The West is missing an observation for period 29 since subjects could not be in the West until period 30. 


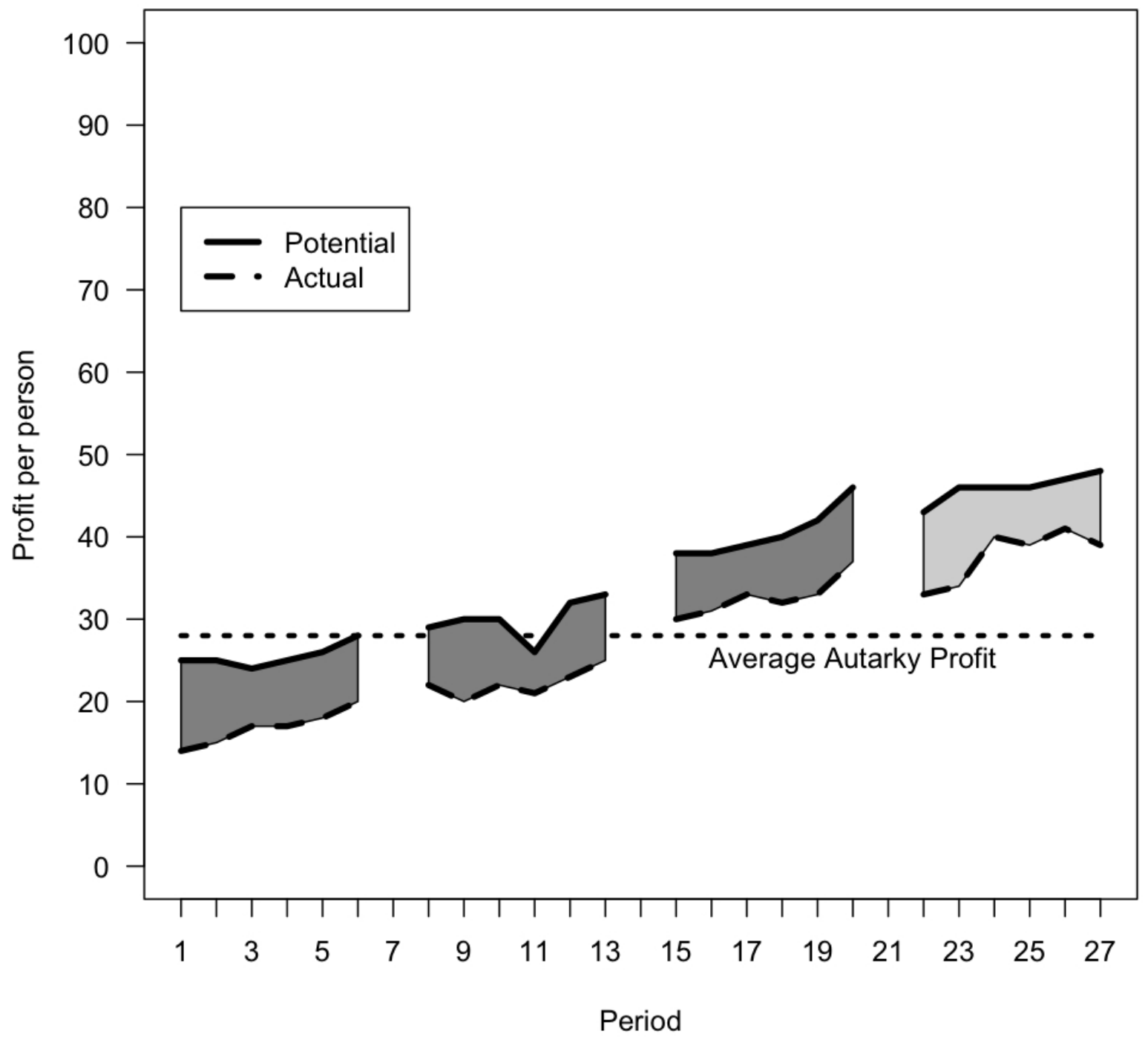

Figure 3. Difference between Potential and Actual Profit in Weeks 1-4

The dark-shaded (light-shaded) area represents the difference between potential and actual profit in pairs (groups of four). 


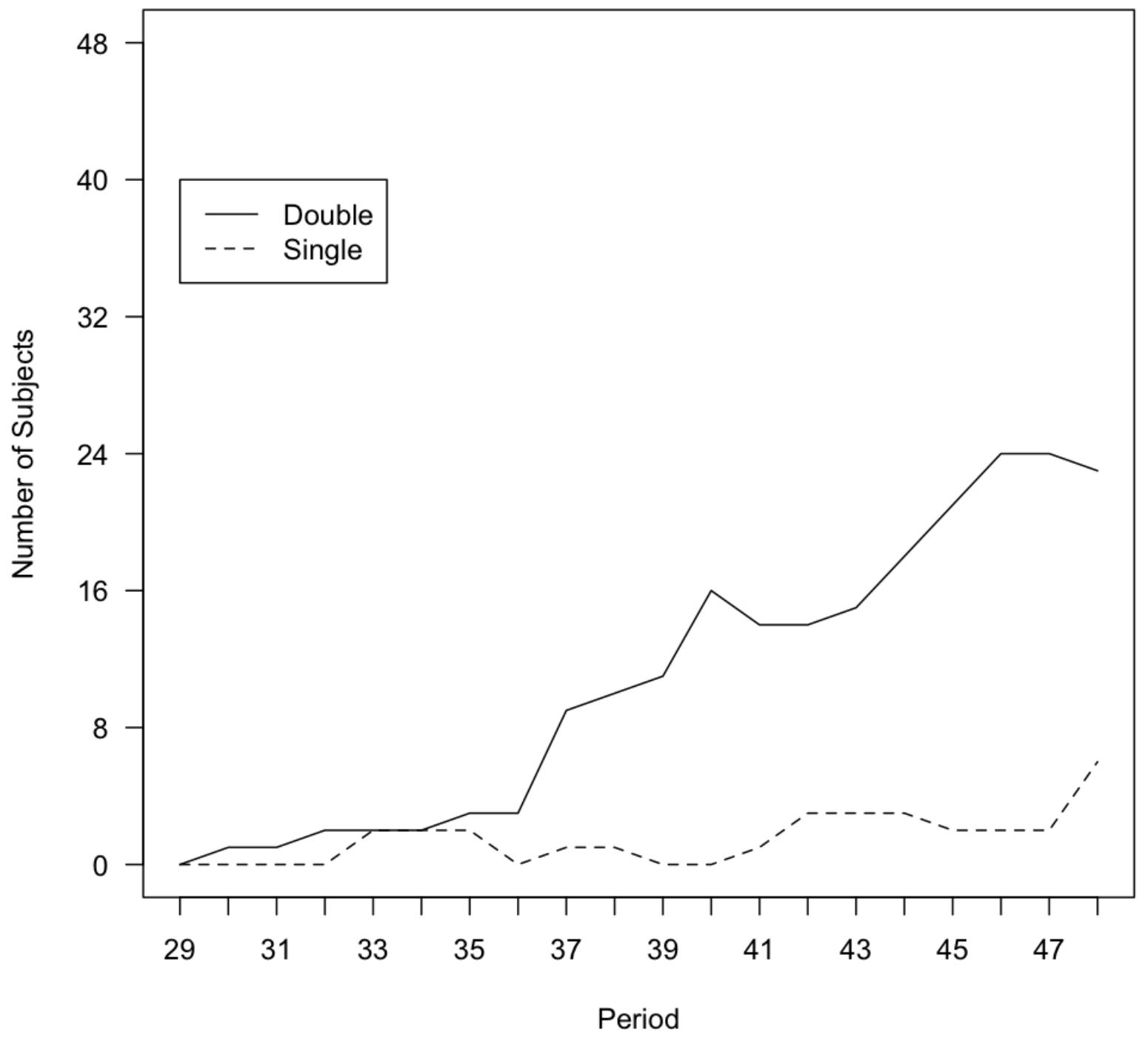

Figure 4. Subjects in the West by Treatment 


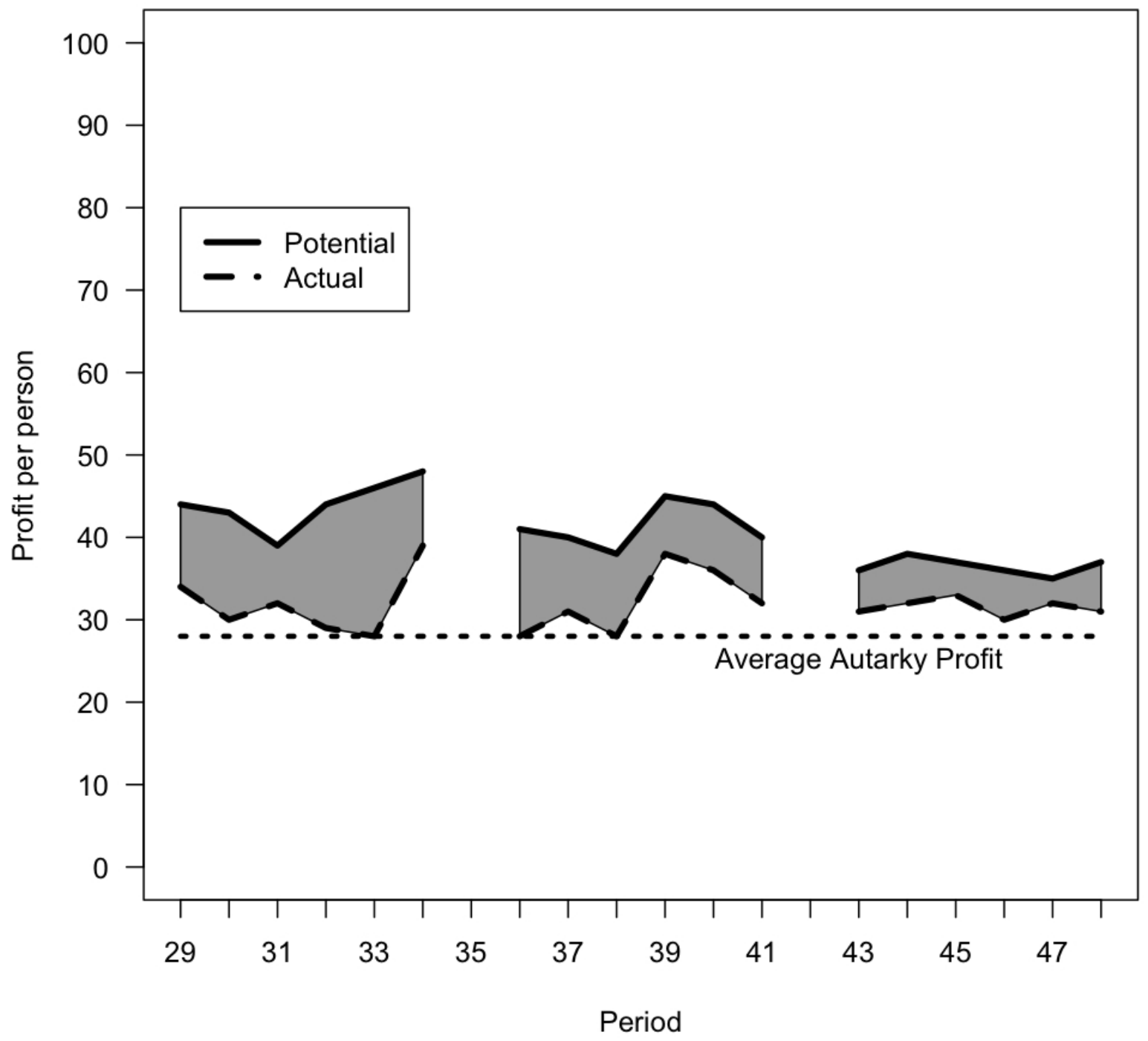

Figure 5. Difference between Potential and Actual Profit in the East 


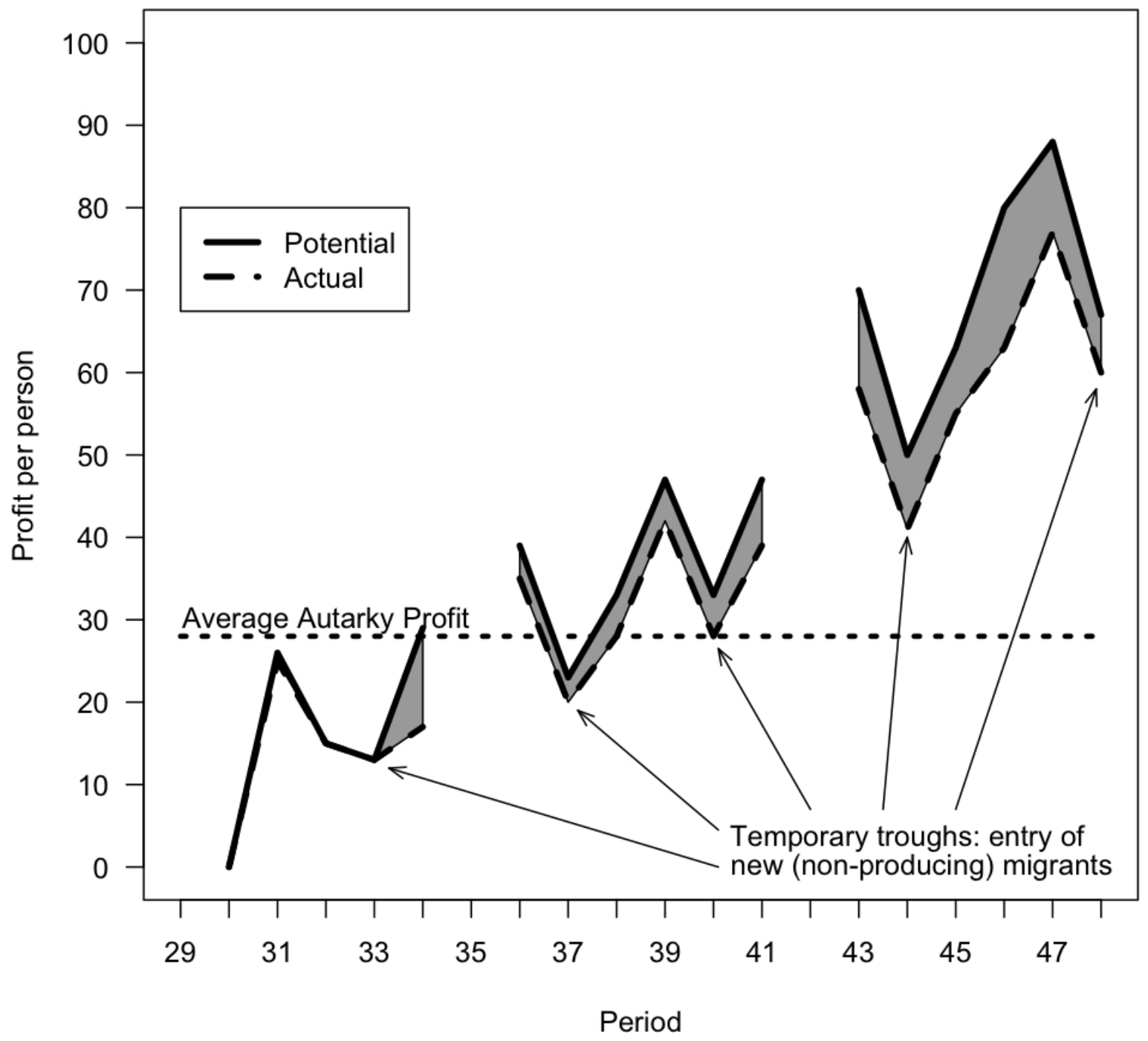

Figure 6. Difference between Potential and Actual Profit in the West 


\section{Economic Science Institute Working Papers}

2009

09-01 Gjerstad, S. Housing Market Price Tier Movements in an Expansion and Collapse.

2008

08-10 Dickhaut, J., Houser, D., Aimone, J., Tila, D. and Johnson, C. Payoffs: Inducing Preferences with Holt-Laury Gambles.

08-09 Stecher, J., Shields, T. and Dickhaut, J. Generating Ambiguity in the Laboratory.

08-08 Stecher, J., Lunawat, R., Pronin, K. and Dickhaut, J. Decision Making and Trade without Probabilities.

08-07 Dickhaut, J., Lungu, O., Smith, V., Xin, B. and Rustichini, A. A Neuronal Mechanism of Choice.

08-06 Anctil, R., Dickhaut, J., Johnson, K., and Kanodia, C. Does Information Transparency Decrease Coordination Failure?

08-05 Tila, D. and Porter, D. Group Prediction in Information Markets With and Without Trading Information and Price Manipulation Incentives.

08-04 Caginalp, G., Hao, L., Porter, D. and Smith, V. Asset Market Reactions to News: An Experimental Study.

08-03 Thomas, C. and Wilson, B. Horizontal Product Differentiation in Auctions and Multilateral Negotiations.

08-02 Oprea, R., Wilson, B. and Zillante, A. War of Attrition: Evidence from a Laboratory Experiment on Market Exit.

08-01 Oprea, R., Porter, D., Hibbert, C., Hanson, R. and Tila, D. Can Manipulators Mislead Prediction Market Observers? 